\title{
Práticas discursivas e manifestações culturais: cenografia e ethos na constituição identitária da mulher na imigração italiana em Nova Prata
}

\author{
Ernani Cesar de Freitas" \\ Iverton Gessé Ribeiro Gonçalves**
}

\section{Resumo}

Este trabalho analisa a constituição da identidade da mulher nas práticas discursivas da imigração italiana em Nova Prata, RS, através da composição da cenografia e do ethos discursivo. A investigação parte das concepções de Maingueneau (2002, 2008 a, 2008b, 2008c) em relação à semântica global, à cenografia e ao ethos discursivo. Os estudos das manifestações culturais e da identidade em Hall (2011, 2013), Bauman (2005), Bourdieu (1989), De Certeau (1995) e Geertz (2008) complementam o aporte teórico em interface. $\mathrm{O}$ corpus de pesquisa é composto por alguns recortes do vídeo-documentário Mulheres e Memórias, que dialogam com outras materialidades discursivas da imigração italiana nessa região. Este trabalho caracteriza-se como descritivo, bibliográfico e documental, de abordagem qualitativa. No fio do discurso da imigração italiana surge um enunciador envaidecido pelo seu trabalho e sua ligação quase materna com a terra mediante cenografias que legitimam sentidos cristalizados pela memória discursiva, relativos à família, à religiosidade e ao cultivo da terra.

Palavras-chave: Práticas discursivas. Manifestações culturais. Identidade. Cenografia. Ethos discursivo.

\footnotetext{
Pós-doutor em Linguística Aplicada (PUC-SP/LAEL). Doutor em Letras (PUCRS). Professor do Programa de Pós-Graduação em Letras da Universidade de Passo Fundo. Professor do Programa de Pós-Graduação em Processos e Manifestações Culturais da Universidade Feevale, Novo Hamburgo, RS. E-mail: ecesar@upf.br

** Doutorando em Letras na Universidade de Passo Fundo. Mestre em Letras pela Universidade de Passo Fundo. Licenciado em Letras pela Universidade de Caxias do Sul. E-mail: hywertthom@hotmail.com
}

Data de submissão: fev. 2017 - Data de aceite: mar. 2017 http://dx.doi.org/10.5335/rdes.v13i1.6750 


\section{Introdução}

O tema que motiva este estudo parte da investigação do sistema semântico global que compõe as práticas discursivas da imigração italiana em Nova Prata, com vistas a averiguar de que forma a identidade da mulher é construída nesse discurso. A relevância deste estudo concretiza-se pela necessidade de registrar, em uma escrita acadêmica, a investigação científica do discurso da imigração italiana que povoa os diferentes campos discursivos da região de Nova Prata, Rio Grande do Sul. Justifica-se este estudo pela preocupação em difundir e promover a discussão sobre as categorias teóricas relativas à cenografia e ao ethos discursivo propostos pela perspectiva enunciativo-discursiva de Maingueneau (2008a, 2008b, 2008c). É parte, também, da justificativa a intenção de criar um espaço de debate sobre o discurso da imigração italiana e a identidade do imigrante que nesse discurso se constrói, a fim de compreender traços das diferenças identitárias como elementos constitutivos da cultura e dos sistemas simbólicos que essas identidades representam.

Para realizar o percurso investigativo pretendido, este artigo se orienta a partir da seguinte questão norteadora: a cenografia e o ethos discursivo permitem investigar as práticas discursivas da imigração italiana em Nova Prata, por meio dos planos constitutivos do discurso, a fim de vislumbrar as manifestações culturais e a construção identitária da mulher nesse discurso. O objetivo que motiva este trabalho é investigar as manifestações culturais e a construção identitária da mulher na imigração italiana através da análise de suas práticas discursivas, com aplicação das categorias teóricas fornecidas pelo estudo da semântica global, em especial, os planos constitutivos do discurso, a cenografia e o ethos discursivo.

A base teórica acionada para este estudo conta com as proposições de Maingueneau (2002, 2008a, 2008b, 2008c), referentes à semântica global, à cenografia e ao ethos discursivo. Completam o embasamento teórico deste artigo os estudos que versam sobre identidade e manifestações culturais realizados por Hall (2006, 2013), Bauman (2005), Bourdieu (1989), De Certeau (1995) e Woodward (2013). O corpus analisado neste estudo é composto por recortes do vídeo-documentário Mulheres e $\mathrm{Me}$ mórias, produzido pela Secretaria $\mathrm{Mu}-$ nicipal de Educação e Cultura de Nova Prata, RS, além de outros materiais que demonstram ser originários do mesmo sistema de restrições semânticas, como textos literários e registros oficiais por parte do Poder Executivo do município. Os procedimentos metodológicos adotados neste trabalho o caracterizam como descritivo, bibliográfico e documental, de abordagem qualitativa.

A estrutura do texto está assim organizada: a primeira seção apresenta algumas considerações sobre os estudos 
da identidade e das manifestações culturais, conforme autores já referidos. A segunda seção descreve o caminho teórico-metodológico proposto por Maingueneau (2008a) no estudo da semântica global, dos planos constitutivos do discurso, da cenografia e do ethos discursivo. A terceira seção apresenta os procedimentos metodológicos pensados para este trabalho e a análise do corpus. Por fim, algumas palavras de considerações finais retomam o percurso realizado neste estudo, no intuito de verificar a pertinência da questão norteadora concebida.

\section{Cultura e identidade: enlaces constitutivos}

Ao tratarmos de identidade e de cultura estamos tratando de duas concepções que estão constitutivamente irmanadas, assim como não podem ser desvinculadas das noções de enunciação e de discursividade. A enunciação, conforme Baronas e Bonatti (2016), é a representação do contexto social, mas também é parte integrante do mundo que está representando, isso porque, conforme Woodward (2013), a representação age simbolicamente para classificar o mundo. A ideia de tomarmos a linguagem como forma de representar o mundo está associada à questão da identidade. Woodward (2013) afirma que as identidades adquirem sentido por meio da linguagem e dos sistemas simbólicos pelos quais são representadas.
É precisamente porque as identidades são construídas dentro e não fora do discurso que nós precisamos compreendê-las como produzidas em locais históricos e institucionais específicos, no interior de formações e práticas discursivas específicas, por estratégias e iniciativas específicas (HALL, 2013, p. 109).

A identidade pode ser compreendida como um fator simbólico e como um fator social, uma vez que o significado fornecido pela cultura, através dos símbolos, é partilhado por uma concordância de subjetividades e é, portanto, social. A marcação simbólica é fonte de sentido das práticas sociais, bem como organizadora das relações sociais (WOODWARD, 2013). Nesse particular, qualquer artefato que tenha sido tomado como objeto simbólico passa a ser um artefato cultural, uma vez que produz significado sobre a pessoa que o utiliza, logo, constitui identidade. Os artefatos culturais, de acordo com Woodward (2013), ao promover a regulação da vida sócia, associam os indivíduos a determinadas identidades.

Vemos, portanto, que estamos enredados num tão grande número de significados fornecidos pela cultura, significados esses que nos dão a dimensão e a compreensão de quem somos, ou de quem devemos ser. As representações que produzem identidades dentro de determinados sistemas simbólicos incluem as práticas de significação e sugerem formas de se dar sentido às experiências. É, então, dentro dos sistemas simbólicos que se faz possível ser o que somos ou o que podemos nos tornar (WOODWARD, 2013). Em outras palavras: 
[...] os discursos e os sistemas de representações constroem os lugares a partir dos quais os indivíduos podem se posicionar e a partir dos quais podem falar (WOODWARD, 2013, p. 18).

Expandindo a discussão sobre identidade e sistemas de representação simbólica, trazemos a assertiva de Bauman (2005) quando diz que a ideia de identidade nasceu da crise de pertencimento, pois "o anseio por identidade vem do desejo de segurança" (BAUMAN, 2005, p. 35). Os seres humanos, em uma necessidade de se classificarem entre subordinados e dominados (WOODWARD, 2013), compreendem suas relações delineadas pelo pertencimento ou pela diferença. Dessa forma, a identidade é gerada numa necessidade de exclusão e classificação entre "nós" e os "outros". Para que essa classificação se sustente, é preciso que o pertencimento identitário pareça natural. Nesse particular, Bauman (2005), fazendo referência à noção identitária construída pelo projeto de criação do estado-nação moderno europeu, afirma que a

[...] naturalidade do pressuposto de que "pertencer-por-nascimento" significava, automática e inequivocamente, pertencer a uma nação foi uma convenção arduamente construída - a aparência de "naturalidade" era tudo, menos "natural" (BAUMAN, 2005, p. 29).

Esse mesmo autor permite-nos falar em três concepções distintas de cultura. Bauman (2005) relata que a ideia de cultura, difundida há alguns séculos, antagoniza-se à noção de natureza. Cultura, nesse sentido, "são escolhas dos seres humanos em oposição aos fatos naturais" (BAUMAN, 2005, p. 67). Em uma visão romântica, cultura pode ser compreendida como os costumes, as crenças, as práticas regulares, mitologia, calendário, entre outros aspectos. Essa visão de cultura pode ser estendida, a nosso ver, a uma visão romântica de identidade, isto é, afirmações positivas do eu em relação às suas experiências. Mas, como veremos em Hall (2013), as afirmações positivas do eu não bastam para explicar a complexidade da identidade. Por ora, interessa-nos a ideia de que as práticas sociais reúnem indivíduos que sentem a necessidade de pertencer a um determinado grupo. Ao retornarmos ao pensamento de Bauman (2005) sobre o estado-nação moderno, compreendemos que a necessidade de pertencimento se apega ao passado, uma vez que as identidades partem de um posicionamento histórico. Woodward (2013) aponta que o retorno ao passado, mesmo que seja apenas imaginado, promove alguma certeza em meio a tanta fluidez e mudanças.

Essa ideia pode ser harmonizada com o pensamento de Bourdieu (1989) sobre o poder simbólico, que é um poder que age sobre os indivíduos, os quais não querem saber que estão subordinados. Esse poder fornece a compreensão do mundo, do homem e do tempo a cada indivíduo. Hall entra em conformidade com esse pensamento ao afirmar que "projetamos a nós mesmos nas identidades culturais ao mesmo tempo que internalizamos 
significados e valores, tornando-os parte de nós" (2013, p. 12).

Cabe destacar, para finalizar, a visão amplamente debatida por Hall (2013) e Woodward (2013) sobre a constituição da identidade a partir da diferença. Numa linguagem comum, ou romantizada, como já apontamos, a identidade pode ser entendida como o ato de fidelidade a um grupo, de origem comum, com os mesmos ideais e que partilham das mesmas características. Nesse particular, Bauman descreve que

[...] um bom número de imigrantes escolheu o novo país esperando, pelo contrário, manter, desenvolver e praticar, sem ser perturbados, as distinções religiosas ou étnicas que estavam ameaçadas em seus países de origem (2005, p. 87).

No entanto, abordando a identidade discursivamente, como é o enfoque central neste trabalho, a identidade nunca será completa. Essa incompletude é associada por Hall (2013) à concepção de différance em Derrida (1991 apud HALL, 2013). Como trabalho discursivo, a identidade exige o estabelecimento de fronteiras simbólicas e, portanto, requer um exterior para constituir-se no interior. Nas palavras de Woodward,

[...] a identidade depende, para existir, de algo fora dela, de outra identidade, de uma identidade que ela não é, de uma identidade que ofereça as condições para que ela exista (2013, p. 8).

Assim, a identidade só pode constituir-se mediante a diferença. Embora homogeneizar a classe subordinada a uma identidade dominante seja um movimento imanente ao dominador, a identidade dominadora depende da identidade dominada e das diferenças que ela lhe fornece para sustentar sua própria constituição e manutenção.

Esta seção propôs-se a debater algumas peculiaridades referentes à identidade e aos sistemas simbólicos, culturais, que nela se constituem. A seção seguinte é dedicada a esclarecer algumas concepções teóricas essenciais e relativas à perspectiva enunciativo-discursiva.

\section{Semântica global: cena singular e enunciador oportuno}

Discorremos aqui sobre a semântica global, tese defendida por Maingueneau (2008a) e pela sua proposição de análise do discurso. A concepção de discurso em Maingueneau (2002, 2008a) não privilegia apenas aspectos linguísticos, nem apenas o caráter histórico do acontecimento enunciativo, mas a dupla composição, sendo discurso "uma dispersão de textos cujo modo de inscrição histórica permite definir como um espaço de regularidades enunciativas" (MAINGUENEAU, 2008a, p. 15). Assim como não executa uma bipartição entre esses dois fatores - língua e história -, também não se privilegia, na análise proposta por Maingueneau (2008a), "esse ou aquele" dentre os planos que constituem o discurso. Todos os planos são relevantes.

Analisar conjuntamente a estrutura e o sentido significa abordar o discurso 
como um sistema de regras que define a especificidade de uma enunciação. Isso requer que a "enunciabilidade" seja vista não apenas como um resultado de atos enunciativos, mas como um fator condicionante da estrutura que possibilitará a enunciação. Em um conjunto de indivíduos, os atos de enunciação não são uma faculdade fornecida por acréscimo, mas um sistema de restrições que condiciona o funcionamento da estrutura enunciativa. Portanto, "é preciso pensar ao mesmo tempo a discursividade como o dito e como o dizer, enunciado e enunciação" (MAINGUENEAU, 2008a, p. 19).

São essenciais neste trabalho os conceitos de formação discursiva e prática discursiva, que se complementam com a ideia de comunidade discursiva e de superfície discursiva. Cabe lembrar que alguns desses termos foram cunhados por Foucault e, posteriormente, por Pêcheux. No entanto, nossa abordagem parte dos estudos de Maingueneau (2008a), que se propõe a reformulá-los sob um novo olhar.

Maingueneau (1997) identifica como comunidade discursiva um grupo ou a organização de grupos regidos por um mesmo sistema de restrições semânticas, de maneira que sua existência se dá pela e na enunciação. A noção de práticas discursivas pode ser caracterizada como o encontro da comunidade discursiva e a formação discursiva, isto é, as práticas discursivas são o resultado das produções que determinada comunidade discursiva realiza, respeitando as coerções impostas pelo sistema semântico.
Embora muitas sejam as filiações do termo "formação discursiva", tomaremos a linha que compreende o sentido global do discurso. A "formação discursiva", de acordo com a definição metodológica de Maingueneau (2008a), corresponde ao sistema de restrições de boa formação semântica. $\mathrm{O}$ conjunto de enunciados produzidos de acordo com as coerções desse sistema pode ser entendido como a "superfície discursiva".

Além dos conceitos já abordados, reservamos este espaço para debruçarmo-nos sobre os planos constitutivos do discurso, integrantes da semântica global, sendo eles: (i) a intertextualidade, (ii) o vocabulário, (iii) os temas, (iv) o estatuto do enunciador e do coenunciador, (v) a dêixis enunciativa, (vi) o modo de enunciação e (vii) o modo de coesão. Maingueneau (2008a, p. 76) desconstrói a noção arquitetônica de discurso em que se analisam os níveis nos quais reside a "verdade do texto". Segundo o autor, o discurso não tem um "fundo", mas um sistema que investe em suas variadas dimensões, por isso a necessidade de abordá-lo em seu conjunto. Mediante a essa configuração da semântica global, é possível investigar minuciosamente o discurso da imigração italiana em Nova Prata, integrando cada um dos planos apontados para corroborar que a identidade - ou identidades - se constrói dentro desse sistema cultural. Freitas (2010), em seus estudos sobre Maingueneau (2008a), assevera que 
[...] todos os planos da discursividade - desde os processos gramaticais até o modo de enunciação e de organização da comunidade discursiva - estão submetidos ao mesmo sistema de restrições, concebido como um filtro que fixa os critérios de enunciabilidade de um discurso (2010, p. 179).

A intertextualidade, primeiro plano descrito por Maingueneau (2008a), refere-se à maneira como determinada formação discursiva se relaciona com seu outro. A intertextualidade vincula-se ao âmbito da heterogeneidade constitutiva, pois é a partir das relações aceitas como legítimas e/ou vetadas por sua ilegitimidade que um sistema global define suas restrições semânticas.

O segundo plano, o do vocabulário, não pode ser tomado de maneira simplesmente operacional, como se estivesse apenas a serviço do intertexto. $\mathrm{O}$ vocabulário, pelo tratamento semântico que recebe, é colocado a serviço de um posicionamento no campo discursivo. (MAINGUENEAU, 2008a). O sistema de restrições que permite ou veta o uso de determinados termos deve poder justificar o estatuto que atribui a cada termo.

Na sequência, os temas tratados por um sistema de semântica global constituem-se no terceiro plano constitutivo. Assim como nenhum discurso possui uma língua própria, mas acessa, de acordo com seu sistema de restrições, o estoque lexical da língua, também nenhum discurso é possuidor exclusivo dos temas que trata. "Nenhum tema é realmente original, dado que ele se reencontra em múltiplos outros discursos, até nos seus adversários" (MAINGUENEAU, 2008a, p. 82), porém remodelados.

Outro plano do discurso no qual consiste a semântica global diz respeito ao estatuto do enunciador e do coenunciador. Não podemos apreender as pessoas do discurso como indivíduos empiricamente demarcados, mas como "coordenadas que comportam os sujeitos do discurso e que a partir destes legitimam o dizer" (FACIN, 2012, p. 42). Conforme Maingueneau (2008a), é a partir de um discurso que serão definidos os estatutos do enunciador (EU) e do coenunciador (TU). Isso significa afirmar que, dentro de determinado sistema de restrições, cada enunciador terá um lugar específico de onde poderá enunciar-se, assim como o coenunciador será situado em outra localização específica estabelecida pelo sistema de restrições.

O discurso comporta marcas da constituição do eu que se situa em um tempo e em um espaço; essas marcas constituem-se em outro plano constitutivo do discurso: a dêixis enunciativa. As pegadas que sinalizam o tempo e o espaço no discurso estão a serviço de um sistema de restrições. Cada discurso instaura sua própria dêixis a partir de seu posicionamento no universo discursivo (MAINGUENEAU, 2008a).

Outro plano constitutivo apontado por Maingueneau (2008a) é o modo de enunciação, isto é, a maneira de dizer. O plano que define o estatuto do enunciador e do coenunciador está interligado ao plano que constitui o modo de enun- 
ciação, isso porque a maneira de dizer definirá os papéis do enunciador e do coenunciador. A maneira de dizer pode ser discutida desde o ponto de vista dos gêneros do discurso, e, como sabemos, os gêneros estabelecem um lugar de onde fala o enunciador, assim como sugerem um lugar para que o coenunciador ocupe.

Resta ainda falarmos de um plano que, segundo Maingueneau (2008a), instaura-se por meio da interdiscursividade: o modo de coesão. De acordo com o autor, a forma como um discurso constrói sua rede de remissões internas também deve ser analisada como parte constituinte e constituída do discurso.

Maingueneau (2008a) destaca, nessa mesma esteira de discussão, que o tom suscitado por um discurso, em sua maneira de dizer, apoia-se em dois aspectos, o caráter e a corporalidade. Com base nos traços psicológicos insurgentes do discurso, vão sendo formadas as disposições mentais do caráter do enunciador que fala nesse discurso. As movimentações textuais e sua maneira de habitar esse corpo enunciativo constroem a corporalidade do enunciador. Podemos perceber que Maingueneau (2008a) vai sugerindo, ao longo de seus estudos, as noções de cenografia e de ethos discursivo. Ora, a construção de um ethos em busca de legitimação requer que o enunciador apoie-se em índices estereotípicos valorizados, ao mesmo tempo em que o coenunciador tira informações desses mesmos índices liberados na enunciação (MAINGUENEAU, 2015). A maneira de enunciar- -se autoriza e requer que o enunciador construa uma imagem de si e, à medida que se esforça por ser validado, os índices discursivos que depreende para a construção de sua imagem contribuem para estabelecer a relação com o coenunciador (AMOSSY, 2008), isso porque "a imagem quer causar impacto e suscitar adesão" (AMOSSY, 2008, p. 17).

De acordo com Maingueneau (2008c), há gêneros que permitem e que exigem a construção de um "dispositivo de fala", enquanto que outros parecem ser mais engessados em sua composição genérica.

O locutor deve dizer construindo o quadro desse dizer, elaborar dispositivos pelos quais o discurso encena seu próprio processo de comunicação, uma encenação inseparável do universo de sentido que o texto procura impor (MAINGUENEAU, 2008c, p. 51).

Esse dispositivo apontado por Maingueneau (2008c, 2013) recebe o nome de cenografia. $\mathrm{O}$ autor ainda destaca que -grafia tem sentido circular, isto é, os planos constitutivos estão todos imbricados nessa construção cenográfica: um discurso ligado a um enunciador e direcionado a um coenunciador, em um lugar e um momento enunciativo, validam a instância que os permite existir. "Por esse motivo, a cenografia está ao mesmo tempo na nascente e no desaguadouro da obra" (MAINGUENEAU, 2008c, p. 51), isto é, da enunciação.

Maingueneau (2010) nos fornece a distinção entre as três cenas que se complementam na enunciação: a cena englobante, a cena genérica e a cenografia. A cena englobante corresponde ao tipo 
de discurso, que pode ser amplamente identificado como: religioso, político, publicitário, filosófico, científico, etc. Quanto à cena genérica, cabe destacar que os locutores só "interagem em cenas englobantes através de gêneros de discurso específicos" (MAINGUENEAU, 2010, p. 206, grifo do autor), isto é, a cena da enunciação é delimitada pelo gênero discursivo. O terceiro nível - a cenografia - exige que a enunciação construa um quadro cênico para legitimar-se, como vimos, é a construção de seu próprio dispositivo de fala.

A análise do discurso concebe para si o ethos como "parte constitutiva da cena da enunciação". Quanto à terminologia, no que concerne à análise do discurso, ethos assume o sentido de uma construção da "imagem de si por meio do discurso" (FREITAS, 2010, p. 179, grifo do autor). Esse posicionamento é fortemente comprovado nas palavras de Maingueneau quando afirma que a "maneira de dizer [...] remete a uma maneira de ser" (2002, p. 99). Maingueneau (2008b) entende que o fiador deve legitimar sua maneira de dizer pelo seu próprio enunciado, já conforme Freitas, não é possível "dissociar a organização dos conteúdos e a legitimação da cena de fala" (2010, p. 180), isso porque desde as escolhas linguísticas até o tratamento dado aos conteúdos podem ser percebidas pistas da imagem do enunciador na construção da cena da enunciação.

A seção seguinte apresenta os procedimentos metodológicos e a análise do corpus.

\section{Metodologia, constituição do corpus e análise}

Esta seção apresenta os procedimentos teórico-metodológicos, breve descrição do corpus de pesquisa e respectiva análise. A análise será apresentada e orientada pelo percurso dos planos constitutivos do discurso integrantes da semântica global (MAINGUENEAU, 2008a), na sequência de cada recorte, visando construir uma unidade cenográfica (cena enunciativa) na constituição do discurso da imigração italiana em Nova Prata, bem como apreender uma imagem de enunciador (ethos discursivo) que denota a identidade da mulher nessa comunidade discursiva.

O corpus deste trabalho constitui-se de recortes do vídeo-documentário Mulheres e Memórias (2009), produzido pela Secretaria Municipal de Educação e Cultura de Nova Prata, como parte das comemorações planejadas para a $5^{\text {a }}$ Primavera dos Museus. $\mathrm{O}$ vídeo apresenta a narrativa da vida de oito mulheres de descendência italiana, em cujos enunciados está retratada a vida comezinha do imigrante italiano, e serve como uma tentativa de resgate histórico para as gerações mais recentes. Para este trabalho, realizamos a análise de apenas uma das narrativas, a considerar a extensão deste texto. Vale destacar que este trabalho recorta os estudos realizados em nível de mestrado, cujo resultado final materializou-se em uma dissertação que executa o percurso analítico sobre as demais narrativas registradas no vídeo-documentário. 


\section{Mulheres e memórias: discursivização identitária}

A seguir, apresentamos o recorte da narrativa a ser analisada.

\section{Quadro 1 - Entrevista 1}

Lourdes Maria Lorenzini Soares - doceira

Eu comecei num casamento foi do Fássio Betin. E, eles tavam precisando de alguém pra ajudar e eu me ofereci. É, eu tinha doze anos, treze anos. E daí começou aquela vontade de cada vez fazer mais e mais e mais. O primeiro bolo de noiva, eu fiz do seu Antônio Manfredi, que saiu mais torto do que direito (risos). Salgado, essas coisas. Eu aprendi vendo os outros, né. Olhando. Observando. E os docinho que eu fui o mais, o que eu mais fiz na vida eu fui aprende em Porto Alegre, né. E daí por diante toda semana eu tinha cinco, seis mil docinho pra fazer [...] Mandei doce pros Estados Unido. Mandei doce pra Polônia. Mandei doce pra Itália. Mandei doce pros... pros árabe. Tudo mundo que vinha aqui queria leva os doce. Quando casou a filha do Cavedon, [...] eu tinha uma viagem marcada pra Bahia, mas... a viagem era de oito dia, né. $E$, nós fomos p... pra Bahia, fiquemo lá até no domingo. Na terça-feira chegamos no Rio de Janeiro. Aí, na quarta-feira eu perguntei pra turma "Quando é que vocês vão... vão chega em casa?" "Só sexta a noite". Eu disse "Mas daí eu não posso. Eu, quinta-feira, tenho que tah em casa". Quarta-feira de manhã, às oito hora, peguei o ônibus ch... saí do Rio de Janeiro pra vim fazer o buffet pra filha do Cavedon. Tud... eu fazia tudo na mão. [...] Eu comprei uma batedeira usada, pequenininha, que durou dois meses. [...] porque quebrou, lotava muito, né. Cheguei fazer duzentos bolo num fim de semana, pro Natal, sozinha.

[...] Era só eu que fazia. Fazia doce pra Passo Fundo. Vinha pedido de Marau, de Passo Fundo, de Bassano, Lagoa Vermelha, Veranópolis, Bento. Eu fazia doce pra tod.... quase toda a redondeza. Que o meu doce é um doce diferenciado. Ninguém mais $f$.... agora começaram fazer. Tem muita gente que faz, né. Mas naquela época ninguém far... fazia. [...] Muito, muito doce. Ih!, a semana que eu tinha pouco era dois mil, três mil. Fazia muito doce pra leva pra fora, né. Só sei dize que [...] eu alevantava ah... ia dormir às dez e levantava às duas pra trabaia, pra pode dá conta, né, do que eu tinha pra fazer. E continuei fazendo doce, até hoje eu tô e fico mal quando não tenho pra fazê.

Fonte: SMEC (2009).
O ambiente da entrevista, de acordo com o que consta na Figura 1, é uma cozinha, a entrevistada está sentada em uma cadeira em lugar de destaque para o vídeo, ao fundo se vê uma mesa de inox e um cilindro de massas. Vê-se, pelas linhas de expressão do rosto da pessoa apresentada, que se trata de uma senhora já em uma idade considerada. Esse aspecto torna-se relevante do ponto de vista da identidade, pois depende do passado para se reafirmar, assim como já nos apresenta uma característica do sistema semântico relativo à intertextualidade. A maneira como a identidade da mulher na imigração italiana se apresenta parte da sabedoria e das experiências de uma anciã, e não de uma jovem, denotando que os mais velhos sempre são os enunciadores mais indicados para falar em nome desse sistema semântico.

\section{Figura 1 - Doceira}

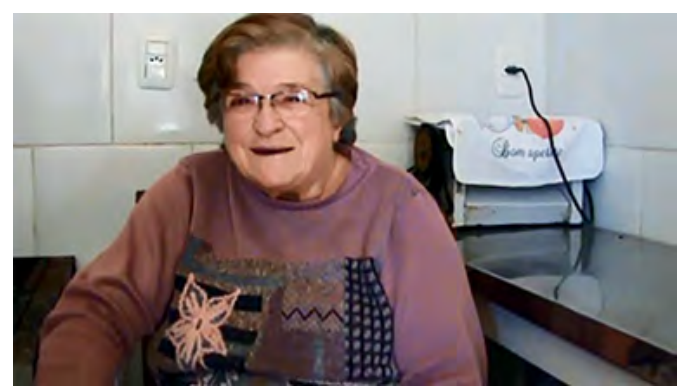

Fonte: SMEC (2009).

O início da carreira profissional do enunciador da Entrevista 1 é demarcado por um casamento. Dentro do sistema de representações simbólicas da imigração italiana, conforme estudo realizado por 
Gonçalves (2015), o casamento é visto como símbolo de validação social. O enunciador, na construção de seu discurso como doceira, dá a primeira investida na legitimação de sua enunciação (MAINGUENEAU, 1997) mediante a prestação de serviço para a preservação da prática do casamento.

A identidade construída no discurso (WOODWARD, 2013) varia de acordo com o desenrolar dos enunciados. Em um primeiro momento, o enunciador identifica-se como ajudante (eles tavam precisando de alguém pra ajudar e eu me ofereci). Dessa ajuda, começa a vontade de cozinhar cada vez mais. De acordo com De Certeau (1995), os símbolos são produzidos por práticas culturais que fornecem um lugar para o indivíduo se constituir, assumindo uma identidade. Entendemos que a culinária seja uma das mais primitivas demonstrações de prática cultural. A proposta de mudança sobre um dado natural sinaliza, em De Certeau (1995), a compreensão daquele dado. $\mathrm{O}$ ato de cozinhar, portanto, não pode ser visto apenas como uma atividade de satisfação das necessidades fisiológicas do homem, pois, se assim fosse, todos os homens se alimentariam da mesma forma. É por se caracterizar como uma utilização compreensiva do espaço que a cozinha é uma prática cultural. $\mathrm{O}$ enunciador que fala enquanto doceira constrói sua identidade a partir da prática cultural da cozinha, por via dos lugares discursivos que essa prática fornece.
Além de a culinária ser genuinamente uma prática cultural, o ato de comer, primitivamente tido como um fator natural da humanidade, torna-se cultural na medida em que as atividades de alimentação se diferenciam de cultura para cultura. De Certeau descreve o conceito de cultura como "aquisição, enquanto distinta do inato. A cultura diz respeito aqui a criação, ao artifício, à ação, em uma dialética que a opõe e a associa à natureza" (1995, p. 194). Comer, dentro do sistema de representações simbólicas da imigração italiana, é uma atividade que se opõe e se associa à natureza, é uma prática social festiva e, por muitas vezes, sagrada. Dessa forma, a enunciação que busca validar-se apela para a construção de uma cenografia específica: a prática da cozinha. $\mathrm{O}$ enunciador vai tecendo seus enunciados como se estivesse guiado por uma receita para legitimar-se.

O primeiro ingrediente de legitimação é o casamento, conforme já apontamos, mas que é retomado pelo enunciador como ingrediente vital para o sucesso na comunidade: "O primeiro bolo de noiva, eu fiz do seu Antônio Manfredi". Geertz entende cultura como

[...] um padrão de significados transmitido historicamente, incorporado em símbolos, um sistema de concepções herdadas expressas em formas simbólicas (2008, p. 60).

$\mathrm{O}$ enunciador em análise deixa-se levar por esse padrão de significados à medida que se permite aprender olhando, observando os demais. As formas simbólicas herdadas são mais alguns ingredientes que o enunciador informa 
ao coenunciador na cenografia de receita que está fazendo sobre como ser um enunciador da culinária da imigração italiana.

A cultura é plural, a guiar-se por De Certeau (1995), pois os símbolos que dão referências ao indivíduo também são plurais. $\mathrm{O}$ agir sobre o espaço é múltiplo e é nessa multiplicidade que o "eu" se esbarra nos limites do "outro". O enunciador-doceira vê-se nessa fronteira de símbolos culturais quando, por necessidade, desloca-se para Porto Alegre a fim de aprender a técnica dos doces, isto é, a maneira de utilização do espaço culinário em que está inserido esse enunciador não dá conta de fornecer símbolos suficientes para sua prática profissional, de modo que é preciso deslocar-se para o espaço do outro, da outra cultura. Eis uma prova de que a cultura é plural. Eis também uma multiplicidade de identidades em deslizamentos: mulher, descendente da imigração italiana, profissional da culinária, etc.

A cenografia construída como uma receita para a legitimação apresenta também o rendimento de seu trabalho. "Dois mil, três mil [doces]", é um rendimento que somente o enunciador que sincretiza os símbolos da própria cultura com as demandas da comunidade é capaz de render. A solicitação cada vez maior de seu trabalho demonstra o seu ajustamento harmonioso à comunidade. De acordo com Geertz, "o homem é um animal amarrado a teias de significados que ele mesmo teceu" (2008, p. 4).
Essa afirmação é refletida na fala da doceira quando informa que seus doces atingiram fronteiras: "Mandei doce pros Estados Unido. Mandei doce pra Polônia. Mandei doce pra Itália. Mandei doce pros... pros árabe". Citar o nome de alguns países é mais uma apimentada que o enunciador, na legitimação de sua fala, lança em sua própria enunciação. O cruzamento de fronteiras é um fator resultante do poder simbólico na empreitada de garantir a cumplicidade dos envolvidos em um mesmo significado. A produção para outros povos e outras culturas sugere, até mesmo, um toque do poder simbólico em que um artefato simbólico se sobrepõe a outra cultura.

Bourdieu (1989) evidencia que a concordância entre as subjetividades é o que garante a objetividade do sentido criado para o mundo. Nesse particular, o doce, segundo o enunciador, é excepcional (o meu doce é um doce diferenciado) - realidade criada no discurso - e, para que o coenunciador valide esse fato como realidade, são apresentadas algumas colheradas de símbolos legitimantes: "Tudo mundo que vinha aqui queria leva os doce".

A narrativa que Dona Lourdes apresenta, na sequência, é um dos ingredientes que mais dá sabor à cenografia construída. A viagem para a Bahia e o Rio de Janeiro precisou ser interrompida para que a doceira cumprisse com os compromissos assumidos na cozinha. Além de abrir mão do lazer, o enunciador ainda destaca a agilidade com que trabalha. 
A imagem que vai se depreendendo é a de uma cozinheira que é capaz de abrir mão do descanso (a viagem era de oito dias [mas] vim fazer o buffet), é capaz de cruzar fronteiras (Mandei pros Estados Unidos), é capaz de alterar a concepção de tempo e espaço (saí do Rio de Janeiro pra vim fazer o buffet pra filha do Cavedon), para que os símbolos de sua cozinha sejam perpetuados no sistema simbólico da imigração italiana.

A identidade, nos postulados de Woodward (2013), é o que dá sentido às práticas sociais. A doceira reforça sua identidade de cozinheira ágil quando destaca que "fazia tudo na mão". Isso significa que não basta afirmar-se como ágil, é preciso corroborar essa identidade nas práticas sociais. Nesse ponto, vemos mais um movimento cenográfico se desenvolvendo: o modo de preparo de uma boa cozinheira deve ser conquistando os méritos pelo sofrimento, a identidade de uma cozinheira bem sucedida no discurso da italianidade começa em uma batedeira pequenininha.

Freitas (2011) afirma que é pelo desenvolvimento da cenografia que o enunciador dá-se a conhecer ao seu coenunciador. No enunciado "Cheguei fazer duzentos bolo num fim de semana, pro Natal, sozinha", temos acesso ao resumo da identidade do enunciador: com poucos recursos (batedeira pequena), o enunciador desafia o tempo (duzentos bolos num fim de semana) para garantir a manutenção das estruturas estruturadas (BOURDIEU, 1989) por meio dos valores religiosos da comunidade (pro Natal), e faz tudo isso sozinha.

Ao unirmos o pensamento de Bourdieu (1989) ao de Geertz (2008), entendemos que a cultura, por sua inclinação política, mapeia as práticas sociais e se perpetua como um organismo público. Vemos, na sequência, que o enunciador descreve o produto de seu trabalho como um bem simbólico que é publico: "fazia doce pra Passo Fundo. Vinha pedido de Marau, de Passo Fundo, de Bassano, Lagoa Vermelha, Veranópolis, Bento". No entanto, esses símbolos são propagados a serviço de um determinado grupo social (a italianidade), autointitulado como proprietário dos sistemas simbólicos, que cria e inova o meio social (o enunciador-mulher da imigração italiana em Nova Prata).

Há um fator que o enunciador da italianidade menciona sem perceber que esse é um resultado do poder simbólico. Ao descrever seu doce, o enunciador destaca: "agora começaram fazer. Tem muita gente que faz, né. Mas naquela época ninguém far... fazia". Segundo Bourdieu, é através da propagação de símbolos e perpetuação de significados que se promove "o consensus acerca do sentido do mundo social” (1989, p. 10, grifo do autor). O trabalho da doceira resulta na propagação de símbolos legitimantes. Seu doce agrada a todas as culturas (Fazia muito doce pra leva pra fora), portanto, todo enunciador que busca legitimar a identidade de doceiro da imigração italiana tem de seguir a re- 
ceita de Dona Lourdes. Sua prática social de cozinheira responsável, dedicada, ágil e audaz (a semana que eu tinha pouco era dois mil, três mil) toma sentido na identidade que constrói para si e serve de parâmetro para outras identidades (agora começaram fazer). A reprodução dos símbolos e significados culinários é a reprodução da ordem social.

Aproveitamos a menção ao enunciado em que Dona Lourdes reconhece que atualmente muitos fazem o trabalho que em outro momento ela detinha exclusividade (agora começaram fazer. Tem muita gente que faz, né. Mas naquela época ninguém far.. fazia.), para analisar o plano da intertextualidade, na semântica global. $\mathrm{O}$ enunciador, ao comentar a concorrência na produção de doces, deixa aparecer no discurso a relação de intertextualidade que se estabelece entre ele e seu "outro". Na distinção de Maingueneau (2008a), a intertextualidade é bipartida em: intertexto e intertextualidade propriamente dita. $\mathrm{O}$ intertexto indica a presença do outro na base textual, sendo concebido como heterogeneidade mostrada. No discurso da imigração italiana, as demarcações do outro na materialidade discursiva são poucas (Tem muita gente que faz, né) e sempre privadas de identidade, o outro é sempre desconhecido (começaram fazer). De acordo com Woodward (2013, p. 37), classificar os grupos em "a norma" e o "desviante" é uma "expressão da identidade". Silva (2013, p. 77) complementa dizendo que a "diferença será sempre do outro", nós sempre tomaremos o que somos como norma. Como se pode ver, o discurso da mulher da imigração italiana em Nova Prata, quando permite que o outro apareça em seu discurso, faz com que essa aparição seja sempre distorcida em relação à norma do sistema simbólico da italianidade.

Em se tratando de intertextualidade no âmbito da heterogeneidade constitutiva, depreendemos das práticas discursivas das mulheres da imigração italiana uma relação de silenciamento e ocultação. Conforme Maingueneau, "um discurso define [...] certa relação com outros campos, segundo sejam citáveis ou não" (2008a, p. 77-78). É pela maneira com que uma formação discursiva se relaciona com as demais que será definida a sua identidade (MAINGUENEAU, 1997). Não podemos dizer que o outro não está presente no discurso da imigração italiana, pelo contrário, o simples fato de esse discurso neutralizar seu "outro" já denota que o outro tem de ser reprimido para não contaminar a norma. Essa atitude discursiva pode ser explicada pelo viés do poder simbólico de Bourdieu (1989), através do qual a classe dominante esforça-se por perpetuar sua localização no centro da cultura, ao mesmo tempo em que tenta ludibriar as classes dominadas com uma falsa integração, enquanto, na realidade, a desloca para a periferia. A falsa integração no discurso das mulheres da imigração italiana ocorre pelo estabelecimento do estatuto do coenunciador como participante do mesmo universo simbólico. 
Entendemos que há poucos resquícios da heterogeneidade mostrada na superfície discursiva do sistema semântico que rege o discurso da imigração italiana em Nova Prata. Já a heterogeneidade constitutiva opera, por mais que oculta e negligenciada, nos fundamentos semânticos dessa formação discursiva.

A heterogeneidade é percebida não somente na identidade da formação discursiva da italianidade, como também na identidade social da imigração italiana. Esse resultado é percebido em um dos últimos elementos da cenografia arquitetada nessa enunciação. O enunciador apresenta mais uma descrição de sua identidade como uma orientação importantíssima para o preparo de uma boa cozinheira: "eu alevantava ah... ia dormir às dez e levantava às duas pra trabaia, pra pode dá conta, né, do que eu tinha pra fazer". Esse aspecto da cenografia ganha força na medida em que aciona uma cena validada (MAINGUENEAU, 2013) proliferada dentro da comunidade discursiva da imigração italiana: levantar cedo é uma orientação necessária para o sucesso. Ao passo que pressupõe uma identidade, não italiana, que não tem sucesso por não levantar cedo, não valorizar a disposição para o trabalho.

Em outro excerto retirado do conto literário $O$ violino do Fuá, presente na obra Sonho italiano: vinho e amor (2013), cuja autora, Zaira Galeazzi, enuncia-se do lugar discursivo descendente da colonização italiana em Nova Prata, encontramos um comportamento semelhante, com alguns novos arranjos: o "outro", nesse enunciado, é o gaúcho, identidade hegemônica na região em que se assentou o imigrante italiano a partir de 1870. Nesse pequeno recorte, podemos ilustrar os desdobramentos da intertextualidade regrada por uma semântica global:

Agora todos cantavam o Hino do Rio Grande do Sul no salão. Miguel com o violino no queixo foi saindo do salão e Lúcia o acompanhou até a charrete e, em seguida, seguiram pela estrada rumo ao novo lar. Ali iria se unir o sangue alemão de Miguel Fuá e o sangue italiano de Lúcia Nardelo para reforçar a raça gaúcha, iniciada pelos centauros dos pampas, os descendentes de Ana Terra. (GALEAZZI, 2013, p. 63).

Esse recorte inscreve-se no campo discursivo literário e estabelece uma relação com outros campos discursivos, o político, o socio-histórico e o étnico-cultural. A entoada do hino do Rio Grande do Sul promove a legitimação do enunciador perante seu coenunciador por meio da intertextualidade. Reconhecer a união do sangue alemão ao sangue italiano é uma relação aceita pelo sistema de restrições da formação discursiva da italianidade e, por esses dois grupos adotarem o Rio Grande do Sul como nova pátria, há um débito para com esse "outro", o solo sul-rio-grandense. Isso justifica a afirmação de que a união dos povos imigrantes europeus vem para reforçar a raça gaúcha. Figura ainda no intertexto a referência que se faz aos centauros dos pampas, descendentes de Ana Terra. Ora, recorrer à Ana Terra, personagem de Érico Veríssimo, ${ }^{1} \mathrm{e}$ aos centauros dos pampas, 
descrição feita por José de Alencar, em $O$ gaúcho, é um recurso utilizado pelo enunciador da imigração italiana para descrever a si mesmo como a continuidade da raça gaúcha. Para evitar ser visto como um intruso no espaço discursivo do gauchismo, o enunciador da formação discursiva da imigração italiana tende a unir-se aos fundamentos de outras formações já instauradas nesse espaço, além disso, dentro do campo literário, esse discurso busca legitimar-se também como literário pela menção de outros discursos já validados, que são citados como seus ancestrais.

Retomando a análise da enunciação da doceira, o tom de excelência na cozinha permite destacar, como caracterização do ethos discursivo, um enunciador-doceira da imigração italiana que lida com as dificuldades e as peripécias do tempo e do espaço com responsabilidade. A base de sua culinária é a determinação em perpetuar os símbolos de sua cultura, pois é só dentro desse sistema simbólico que sua identidade ganha sentido.

Admitir o ethos construído pela Entrevista 1 como fiador do discurso das mulheres da imigração italiana em Nova Prata é admitir que o processo identitário não se completa aqui. A identidade, não essencialista, inacabada (HALL, 2013), da cozinheira continuará buscando símbolos de identificação na culinária, até porque comer é uma prática cultural que não se esgota. Dessa forma, o ethos discursivo do enunciador em análise não apenas se oferece para continuar trabalhando pela comunidade, como também se autocaracteriza como necessário dentro desse sistema cultural. Assim como o sistema precisa dele para ser propagado, ele precisa do sistema para viver sua identidade (WOODWARD, 2013): "fico mal quando não tenho [doce] pra fazê".

O plano da dêixis enunciativa não se resume à delimitação cronológica das práticas discursivas, nem à circunscrição topográfica. Esse plano diz respeito ao tempo e contexto enunciativos evocados para a legitimação da enunciação. $\mathrm{Na}$ prática discursiva da imigração italiana em Nova Prata, com um recorte sobre as mulheres idosas, conforme já citado, entendemos que a referência temporal característica é o passado que se faz aparecer na enunciação presente. Essa estratégia está fortemente ligada à noção de memória da cultura e à tradição. De acordo com Hall (2013), os recursos históricos são fertilizantes para a promoção de identidades e os grupos sociais tradicionais tendem, por esse motivo, a venerar o passado, valorizar os símbolos históricos e apegar-se à tradição como uma forma de lidar com o tempo e espaço (HALL, 2006).

Enunciar-se em um tempo em que o coenunciador não teve acesso é garantir a ele a participação na fundação de crenças, mitos e valores. Além dessa expressão, é marcante o emprego verbo-temporal no passado. Isso significa que as identidades são vividas a partir de símbolos pretéritos, e chama a atenção que, depois de discorrer sobre a própria vivência, a entrevistada encerra sua fala 
com uma avaliação no presente, denotando que o tempo presente não tem espaço ativo nesse discurso, apenas reflete sobre o passado: "Fico mal quando não tenho pra fazê". O tempo cronológico passado é atualizado na enunciação para que se viva as representações simbólicas da identidade e o presente submete-se a ponderar sobre o poder simbólico.

Quanto ao espaço, a entrevista instaura um espaço de trabalho, de construção tanto da comunidade como das identidades. O espaço de sofrimento, de escassez e de labuta constitui o contexto da imigração, da colonização e da descendência da italianidade, esse é o contexto próprio dessa formação discursiva. Para reforçar essa peculiaridade, recorremos, mais uma vez, ao texto literário. Geraldo Farina, escritor e historiador pratense, em seu livro Memórias do cotidiano (1987), tece uma crônica intitulada Topografia, na qual podemos perceber a mesma preocupação com o trabalho, com o cultivo da terra, das memórias e das identidades fornecidas pelo sistema cultural da italianidade. A descrição que Farina (1987) faz reflete perfeitamente o contexto enunciativo no qual se inscreve o discurso da imigração italiana:

Conheço o aroma penetrante desta terra e conheço quase todos seus tortuosos caminhos. Um dia terei férias para pisar todo este chão. Mesmo assim, já vejo o agricultor voltando suado ao anoitecer ruminando as pedras por onde caminha. Vejo o motorista vencendo centenas de quilômetros. Vejo o pedreiro batendo com força a rocha que se converterá em suaves lajes de algum passeio público ou degraus para muita gente subir. Vejo a menina levando a vaca pastar...
Pouco a pouco vou aprendendo que a terra é todo o meu corpo e que as fontes, os regatos, os rios correm em minhas veias, assim como corre o negro vinho. Amo demais essa terra e morro com ela um pouco todos os dias. (FARINA, 1987, p. 9).

Nesse excerto, o enunciador faz uma descrição da terra como algo mais íntimo que um lar, a terra é o próprio corpo. Nesse chão de intenso trabalho é onde o enunciador deseja estar até mesmo no momento de descanso, nas férias. As profissões e atividades que vão sendo descritas não estão expostas no cenário enunciativo, são parte do cenário, tal como ocorre na Entrevista 1. Na terra onde é preciso que todos trabalhem, até mesmo as crianças têm seus afazeres. $\mathrm{O}$ sangue (negro vinho) dessa terra, desse corpo, desse sistema de representações simbólicas não é natural, é fruto do trabalho, é fruto da cultura. Eis a maneira como o enunciador ocupa o espaço, trabalhando, porque trabalho é vida. Trabalhar é sinônimo de estar vivo, pois o trabalho é a forma como o indivíduo se sente italiano.

Com base em Maingueneau (1997), afirmamos que nenhuma dêixis é inédita. O tripé pessoa-tempo-espaço parte da dêixis fundadora. A dêixis fundadora da imigração italiana capta uma forma de inscrição na história em que o trabalho e o ardor da sobrevivência regulam o tempo, compõem o espaço e constroem o ethos desbravador do descendente da imigração. Para reforçar esse resultado, recuperamos aqui, na categoria de pessoa, a descrição fornecida pelo site 
da Prefeitura Municipal de Nova Prata. Pelo que consta na página virtual:

O colono italiano cultivou suas belas canções, seus costumes, o jogo da mora, da bocha e das cartas. Essas tradições ainda são encontradas em Nova Prata na sua forma mais genuína e pura (NOVA PRATA, 2015).

A identidade construída pela italianidade exige que os indivíduos mantenham-se fiéis às tradições e aos costumes e conservem os traços culturais da forma mais genuína e pura possível. Nesses dois vocábulos (genuína e pura) (NOVA PRATA, 2015), reforça-se, mais uma vez, a relação de silenciamento do "outro" no âmbito da intertextualidade, como forma de garantir a purificação desse discurso através da classificação identitária e da exclusão entre "nós" e os "outros".

Após nos debruçarmos sobre esses dois planos, o da intertextualidade e o da dêixis enunciativa, somos conduzidos pela própria análise a explorar o plano que contempla o estatuto do enunciador e do coenunciador. Como já vimos, a relação intertextual que o enunciador da imigração italiana estabelece com seu outro é uma relação de sobreposição e domínio, isto é, a identidade do outro sofre um apagamento quando passa a ser diluída na identidade do imigrante italiano, com a peculiaridade de que os fatores identitários alheios que são incorporados à identidade da imigração italiana são discursivizados, doravante, como se sempre tivessem pertencido a essa conjuntura cultural e identitária. Portanto, o estatuto que o enunciador estabelece para si é o de autoridade. A mulher da imigração italiana é dotada, após ter cumprido com as demandas culturais a ela impostas, de toda a sabedoria para ensinar as gerações mais novas e preservar o sistema simbólico que a identifica.

Dentro do sistema de restrições da imigração italiana em Nova Prata, o enunciador posiciona-se como marco inicial do discurso. É a partir desse enunciador que se tem acesso à historicidade, fazendo transparecer que antes dele nada houve, nem mesmo discurso. Os enunciados: "Eu comecei num casamento" e "[...] eles tavam precisando de alguém pra ajudar e eu me ofereci" comportam o entendimento de que o início da carreira de trabalho é a fala primeira que se ouve ressoar no interdiscurso. A ajuda oferecida na festa de casamento demarca que, antes desse enunciador, o sistema de representações simbólicas estava ameaçado pelo assombro de ser exterminado. $\mathrm{O}$ enunciador apresenta-se como uma peça essencial para a revitalização do sistema cultural através de um fenômeno simbólico, o casamento.

Maingueneau (2008a) descreve que a imagem do enunciador construída para validar a enunciação tem de se assemelhar a um Sujeito Absoluto, valorizado e autorizado pela formação discursiva a partir da qual o sujeito se enuncia. Esse estatuto exigido do enunciador-mulher da imigração italiana parece atender a todas as expectativas: " $E$ daí começou aquela vontade de cada vez fazer mais e mais e mais". Como se pode inferir, 
ao longo da enunciação, o enunciador vai aproximando a imagem de si ao Sujeito Absoluto do discurso da mulher da imigração italiana. O desejo de fazer mais e mais aponta para um constante anseio de aprovação da identidade como cozinheira, mas não como mais uma. $\mathrm{O}$ enunciador constrói uma imagem de si como desejoso por oferecer o melhor de seus préstimos: "o meu doce é um doce diferenciado". A imagem de si construída no discurso nos encaminha para uma identidade de exclusividade e excelência, que serve como fiador desse discurso. Essa identidade, além de buscar uma afirmação social, depreende sua faceta política, em que é preciso ser parte da cultura dominante e, para isso, é preciso atender aos critérios que a cultura dominante impõe.

É apontado pelo enunciador o fato de existirem outras doceiras, no entanto, conforme seu discurso, há um diferencial em seu trabalho: a ansiedade por garantir, através de diversos meios simbólicos, sua participação na cultura dominante - a cultura da imigração italiana. Nesse enunciado, é reforçada a necessidade de se dedicar a uma comunidade que visa ser reconhecida pela qualidade de seu fazer. A maneira de utilização do espaço (DE CERTEAU, 1995) não é só identificada como prática para obter recursos de sobrevivência, mas também, por essa maneira, é compreendida como forma de obter o reconhecimento de comunidade modelo. O sistema de representações simbólicas exige que seus enunciadores façam do trabalho um símbolo de realização, um símbolo de felicidade. Executar suas atividades em prol da comunidade, investindo dedicação em seu fazer, significa oferecer o melhor de seu trabalho: "fico mal quando não tenho pra fazê".

Ao mesmo tempo em que do estatuto do enunciador depreende-se uma imagem de zelo e excelência no trabalho, o estatuto do coenunciador é definido como participante do mesmo sistema de representações, isto é, a concordância de subjetividades (BOURDIEU, 1989). Quando o enunciador tece o enunciado "Muito, muito doce. Ih!, a semana que eu tinha pouco era dois mil, três mil. Fazia muito doce pra leva pra fora, né. Só sei dize que [...] eu alevantava ah... ia dormir às dez e levantava às duas pra trabaia, pra pode dá conta, né", não só constrói na enunciação um efeito de legitimação no discurso da imigração, como também espera que o coenunciador reconheça, por meio da cenografia construída até o momento, a excelência de seu trabalho. Somente uma doceira dedicada, que entende o trabalho como uma benesse divina e que se doa para a comunidade, pode ser reconhecida em seu discurso, de forma que os números causam um deslumbramento (era dois mil, três mil [doces] / ia dormir às dez e levantava às duas pra trabaia) e reforçam a primazia de seu trabalho. Além do mais, supõe-se, pelas marcas discursivas, que o coenunciador esteja de acordo com a crença de que uma boa doceira é aquela que acumula tantos trabalhos em seu discurso a ponto de não poder mensurá-los: "Tudo 
mundo que vinha aqui queria leva os doce". Essa crença, discursivamente descrita como cena validada (MAINGUENEAU, 2013), é parte do processo de estereotipagem (AMOSSY, 2008) da qual, supõe-se, o coenunciador partilha.

A situação de enunciação segue seu percurso de legitimação, conforme Maingueneau (2013), pelas recorrências que $o$ enunciador faz às dificuldades que enfrentou para atender à comunidade. Nesse ponto, destacamos a relação que se estabelece entre o ethos discursivo construído pelo enunciador e o modo de enunciação, um dos planos constitutivos da semântica global. O modo de enunciação, em Maingueneau (2008a), é indiscutivelmente a maneira de dizer. Já vimos, conforme atesta Maingueneau, que a "maneira de dizer [...] remete a uma maneira de ser" (2002, p. 99). A maneira como o enunciador-mulher da imigração italiana constrói a cenografia e a imagem de si mesmo no discurso (ethos discursivo) deixa transparecer uma maneira de ser culturalmente regrada e convicta da frutífera normatização que representa $o$ poder do sistema simbólico no qual está inserido.

As modalizações que, aparentemente ingênuas, registram-se dão ao discurso um ar de receita a ser ensinada ao coenunciador: "Quarta-feira de manhã, às oito hora, peguei o ônibus ch... saí do Rio de Janeiro pra vim fazer o buffet pra filha do Cavedon". As obrigações são destacadas no enunciado "saí do Rio de Janeiro pra vim fazer o buffet", e deno- tam um indivíduo comprometido com sua identidade cultural. Relacionando esses enunciados com o que aponta Geertz (2008), quando afirma que a cultura serve como uma teia semiótica na qual o indivíduo se vê enredado, podemos perceber que, no estudo das manifestações culturais no âmbito da imigração italiana em Nova Prata, há um sujeito envolvido por um código cultural que valoriza ferrenhamente o trabalho e que se vê preso a ele como forma de dar sentido à sua existência.

O modo de enunciação toma cada vez mais força na investida que o enunciador faz em busca da legitimação. A doceira validada por esse sistema simbólico pode, por seu estatuto, afirmar que: "Ninguém mais f.... agora começaram fazer. Tem muita gente que faz, né. Mas naquela época ninguém far... fazia". Admitir que outros, na atualidade, fazem doces é registrar que a comunidade prosperou, mas essa prosperidade e praticidade atuais se opõem, através do "mas", às dificuldades que a doceira enfrentou em sua época, uma época em que só ela fazia doces, ninguém mais. $\mathrm{O}$ tema e o vocabulário são outros planos que podem ser percebidos na construção da cenografia que constitui o ethos discursivo, por meio do tratamento semântico dado à vida e ao trabalho, e estão interligados ao modo de enunciação. Quando a doceira afirma: "fico mal quando não tenho pra fazê", capta-se uma lição de que a vida precisa ter uma ocupação. A vida foi ocupada, em grande parte de seu 
tempo, com trabalhos que alimentavam o sistema cultural que dá significado à sua vida. Não podemos passar pela vida sem contribuir com o sistema do qual fazemos parte. A forma de contribuição valorizada pelo sistema semântico global da imigração italiana é o trabalho.

Ainda discorrendo sobre a construção dos enunciados nessa entrevista, podemos perceber que a forma como o enunciador constrói seu discurso é regulada pela semântica global. Um dos planos constitutivos que falta ser abordado é o modo de coesão. Maingueneau (2008a) destaca que a construção de parágrafos e a maneira como o enunciador argumenta ou se desloca de um tema a outro são regulados a fim de garantir um todo coeso de sentido. No discurso da imigração italiana, o trabalho, o casamento, a família e o zelo pela comunidade são aspectos que exigem grande investimento temporal, de forma que ocupar o tempo em outras atividades parece ser desnecessário. As obrigações da mulher dentro da formação discursiva da italianidade não permitem que ela se estenda em sua narrativa. Os enunciados curtos e a passagem brusca de um tema a outro (início da profissão aos doze anos, o primeiro bolo de casamento, a produção e $o$ envio de doces, o curso em Porto Alegre, a volta da viagem para fazer o buffet, a batedeira pequena, os duzentos bolos para o Natal, etc.) nos permitem apreender um enunciador que se ocupa mais com os trabalhos que com a própria enunciação e, portanto, não pode se alongar em seu discurso.
A argumentação do enunciador, outra característica evidenciada pelo modo de coesão, destaca um sujeito breve e econômico em suas palavras: "Eu aprendi vendo os outros, né. Olhando. Observando. I eu fazia tudo na mão". A brevidade nos enunciados pressupõe que o coenunciador, parceiro da mesma bagagem dóxica, não precisa ter acesso aos argumentos na superfície discursiva, pois já os conhece por meio dos estereótipos culturais inculcados pelo poder simbólico e os ativa no momento da enunciação que o interpela.

Geertz (2008) aponta que a cultura oferece modelos até mesmo para nossos sentimentos. No caso do enunciador encontrado nas práticas discursivas da imigração italiana, o modelo de amor com o trabalho e compromisso com a qualidade da comunidade e a valorização da oportunidade de contribuir para com a manutenção e satisfação do grupo social, associados ao aspecto religioso, são características que demonstram que o sistema cultural forneceu modelos que parametrizaram, por meio do poder simbólico, as práticas culturais narradas. Mostram também que essas manifestações da cultura da imigração italiana são materializadas no discurso, ressaltando ainda mais que até mesmo o discurso é regulado por um sistema de coerções, através dos planos constitutivos analisados, que atenda às referências culturais dadas pelo sistema de representação simbólica.

Os valores nos quais se apoia o enunciador-mulher da imigração italiana 
estão fundados no entendimento de que é preciso ser útil na vida e que a negação ao trabalho representa uma negação do cultivo de si próprio, assim como aponta para uma negação do cultivo da memória da italianidade. O comportamento que se depreende do ethos encarna e faz o coenunciador encarnar os valores de que Deus, o casamento, a família, a comunidade são estruturas estruturantes para promover o sucesso no trabalho.

A cenografia que tematiza a vida como oficina de trabalho só é validada porque está localizada em um contexto específico de enunciação, a imigração italiana. Percebemos essa descrição nas palavras de Ophélia Sander Ghidini, poetisa pratense, no texto que consta no encerramento de um livro histórico do município, 100 anos da cidade de Nova Prata, de Zaira Galeazzi ([199?], p. 201), intitulado Homenageando os 120 anos da Imigração Italiana:

E tu, meu Rio Grande do Sul? Filho da Pátria querida, terra de valores sem fim, toda virgem te entregaste, gerando filhos de outras raças que, entrelaçando crenças e amor, povoaram nossos rincões.

Sábios homens descarregando bagagens de esperança confiaram em Deus e triunfaram pela fé.

Um dia, viram no milagre da vindima transbordar o vinho novo e na espiga dourada do trigal sem flor, crescer o sagrado pão de cada dia.

Heróis do passado, longe está o bater do machado sangrando a árvore virgem que alimentou esperanças (GHIDINI, ([199?], p. 201).

O enunciador descreve o Rio Grande do Sul como filho da pátria querida,
Brasil, e engrandece esse filho como terra de valores sem fim. Podemos identificar uma contradição na descrição que relaciona terra de valores sem fim e toda virgem te entregaste. Poderíamos indagar a que se deve a adjetivação terra de valores sem fim se a terra virgem supõe um espaço ainda sem cultivo. Essa contradição é resolvida se analisarmos o jogo que ocorre no tempo enunciativo. Já vimos que, no discurso da imigração italiana, o tempo passado oportuniza viver as identidades, enquanto que o presente enunciativo serve apenas para apreciação dos valores simbólicos. Aqui se confirma essa interpretação, pois o enunciador descreve a terra de valores sem fim em um tempo presente e vive a identidade desbravadora e viril daquele que possui uma virgem no passado enunciativo.

Virgem também sugere um traço da heterogeneidade constitutiva. Considerar a posse de uma terra virgem é admitir que os povos pioneiros, conforme Farina (1986), os índios coroados, nada produziram nesse solo e que foi nas mãos do imigrante italiano (sábios homens) que a terra tornou-se fértil (Um dia, viram no milagre da vindima transbordar o vinho novo e na espiga dourada do trigal sem flor, crescer o sagrado pão de cada dia). A fé aparece mais uma vez como estrutura estruturante (triunfaram pela fé) e, no plano da intertextualidade, busca uma dêixis fundadora no discurso bíblico. Das cartas que o apóstolo Paulo escreve aos hebreus, uma delas, o capítulo 
11, destaca os cristãos primitivos como exemplos que triunfaram pela fé. (HEBREUS, 1980, p. 1314). É invocando a historicidade dessa dêixis fundadora que o enunciador tenta legitimar a identidade da imigração italiana como exemplos de fé na nova terra.

Os heróis do passado reforçam a imagem desbravadora do imigrante. Silva (2013) aponta para o fato de os mitos fundadores serem colocados em pedestais de heroísmo para promover o sentimento de pertencimento a uma identidade. Além disso, mais uma vez, recorre-se à descrição da terra, da natureza e de seus recursos como virgens. Pela valorização que se dá ao casamento, cena validada pelos estereótipos culturais da italianidade, podemos estabelecer um relação amorosa entre os heróis do passado e a virgem. Somente um homem destemido, sábio e fervoroso na fé é digno de tocar a virgindade dessa terra. $\mathrm{O}$ casamento ligado ao discurso que valoriza o trabalho ocorre também entre o homem e a terra.

O corpus analisado neste estudo é um portal para o mundo ético da imigração italiana. A comunidade discursiva da italianidade ancora-se em cenas validadas em que os estereótipos construídos em um passado remoto servem de alicerce para que as identidades sejam vividas e o poder simbólico preservado. $\mathrm{O}$ discurso não une passado e presente, mas traz à tona um passado de sofrimento, bravura, fé e muito trabalho e provoca na enunciação presente um sentimento saudosista.

\section{Considerações finais}

Este trabalho partiu da temática que engloba as práticas discursivas das mulheres, as manifestações culturais e a identidade através da cenografia e do ethos discursivo da imigração italiana em Nova Prata, RS. A justificativa apresentada para a realização desta escrita acadêmica inclui o desejo de contribuir com os estudos de análise do discurso e ampliá-los com base no quadro teórico-metodológico de Maingueneau (2002, 2008a, 2008b, 2008c), mediante os postulados da semântica global, da cenografia e do ethos discursivo. Como contribuição social, intentamos trazer à tona as bases discursivas que fornecem traços identitários para os indivíduos que se enunciam a partir do discurso das mulheres da imigração italiana. Entendemos que as diferenças, as discriminações e os traços de desigualdade que envolvem tanto os grupos sociais da imigração italiana quanto grupos de outras formações discursivas podem ser amenizados por meio de uma leitura discursiva que compreenda os traços identitários (raça, nacionalidade, gênero, crenças) como lugares discursivos, e não como traços essencialistas e biologicizantes, como misticamente se apregoa.

A intensão de abordar as manifestações culturais e a identidade como construtos discursivos foi possibilitada pelos recursos da semântica global. (MAINGUENEAU, 2008a). Cada um dos planos constitutivos analisados 
possibilitou identificar traços identitários que se embasavam em estereótipos tidos como bens simbólicos da cultura da imigração italiana. A intertextualidade, por exemplo, permitiu perceber que a relação entre o discurso da imigração italiana e outra formação discursiva é uma relação de abafamento. Isso significa que o outro é sempre uma ameaça para a norma da italianidade e deve ser silenciado. Manter o discurso livre de qualquer contaminação exterior parece ser uma característica identitária do enunciador-mulher da imigração italiana em Nova Prata.

O entrelaçar dos planos constitutivos nos permite ter acesso a um movimento enunciativo que enlaça enunciador e coenunciador no momento único da enunciação. Os planos que dizem respeito ao modo de enunciação e ao estatuto do enunciador e do coenunciador trazem à superfície discursiva a imagem de um corpo (identidade) que fala e que busca adesão (poder simbólico). A dêixis enunciativa (historicidade da imigração italiana) fornece pistas para entender as estratégias de legitimação lançadas na enunciação como elementos da cenografia.

Este artigo desenvolveu-se com vistas a responder a seguinte problematização: a cenografia e o ethos discursivo permitem investigar as práticas discursivas da imigração italiana em Nova Prata, por meio dos planos constitutivos do discurso, a fim de vislumbrar as manifestações culturais e a construção identitária da mulher nesse discurso.
Os resultados obtidos apontam para o fato de que as manifestações culturais são acessíveis no discurso e, portanto, a estruturação de um sistema semântico global está a serviço de um sistema de representações simbólicas. O discurso das mulheres não é apenas onde se apreendem as características culturais da italianidade, mas é onde se vive e se cultua cada uma das facetas culturais impostas por esse sistema. Corroboramos que a investigação dos planos constitutivos do discurso permitiu acessar desde as peculiaridades mínimas até as movimentações globais da identidade e da cultura da italianidade e que, dessa análise, apreendemos uma cenografia fortemente ancorada em valores culturais e um ethos comprometido com as imposições do poder simbólico por meio da preservação das tradições.

Ratificamos que a cenografia insistentemente construída para a legitimação da enunciação da mulher na imigração italiana é aquela que monta o cenário de trabalho, de escassez de recursos e de determinação. Para reforçar essa cenografia, a enunciação recorre aos aspectos de validação fornecidos pela dêixis fundadora. Portanto, sim, a temporalidade demarcada no passado histórico é um dos elementos de legitimação da enunciação. O ethos depreendido dessa enunciação deixa perceber um comportamento da mulher comprometida com o progresso da comunidade. A imagem que constrói de si é dependente da cenografia de trabalho. A atividade humana como recurso 
de sobrevivência é uma maneira não só de ocupar o espaço, mas de respirar, de viver. O fiador elaborado por esses índices é o de indivíduo cultivado pelo trabalho, tanto quanto a terra cultivada pela cultura.

O objetivo que motivou este trabalho foi o de investigar as manifestações culturais e a construção identitária da mulher na imigração italiana através da análise de suas práticas discursivas, com aplicação das categorias teóricas inseridas no contexto da semântica global, em especial, os planos constitutivos do discurso: a cenografia e o ethos discursivo. As manifestações culturais aparecem, especificamente, através do casamento como símbolo de validação perante a comunidade, do apego à terra como sentido da vida, da propagação dos símbolos culturais de fé e religiosidade como condição para a satisfação pessoal e da necessidade de instaurar um tempo e um espaço em que o imigrante seja glorificado por seus feitos. Essas características culturais são materializadas na cenografia enunciativa por estarem afinadas ao domínio ideológico dessa cultura. Resultante do movimento enunciativo dissecado pelos planos da semântica global, a imagem do enunciador-mulher revela um ethos puritano, que defende sua cultura como forma única de habitar o espaço, um ethos que abre os sulcos da própria existência enunciativa para lançar as sementes dos bens simbólicos como forma de cultivar seu sistema cultural e de posar com uma identidade venerável pelos feitos bravios.
Por ora, apresentamos os resultados garimpados como uma singela contribuição para os futuros estudos na perspectiva enunciativo-discursiva e esperamos que essa ínfima contribuição possa servir como elemento motivador para muitas outras pesquisas na mesma esteira teórico-metodológica.

\section{Discursive practices and cultural manifestations:} scenography and ethos in the identity constitution of women in Italian immigration in Nova Prata

\section{Abstract}

This work analyzes the woman's identity constitution in the discursive practice of italian immigration in Nova Prata - RS, through the composition of the scenography and the discursive ethos. The investigation starts from the conceptions of Maingueneau (2002, 2008a, 2008b, 2008c), in relation the global semantic, the scenography and discursive ethos. The studies of the cultural manifestations and of identity in Hall (2013), Bauman (2005), Bourdieu (1989), De Certeau (1995) and Geertz (2008) complement the theoretical contribution in interface. The corpus this research is composed by clip of the documentary video Mulheres e Memórias (Women and Memory) that dialogue with other discursive materialities of Italian immigration in this region. This work is characterized as descriptive, bibliographic and documentary, of qualitative approach. On the string of the discourse of the Italian 
immigration aris a proud enunciator by his work and his relation almost maternal with the earth through scenographyies that legitimize meaning crystallized by discursive memory, relating to family, to religiosity and to tillage of the earth.

Keywords: Discursive Practice. Cultural Manifestation. Identity. Scenography. Discursive Ethos.

\section{Nota}

1 Ana Terra é uma personagem que integra o primeiro volume da trilogia $O$ Tempo e o Vento, obra-prima do escritor Érico Veríssimo. No contexto da narrativa, Ana Terra serve como modelo idealizado da identidade gaúcha, discursivizada como uma mulher aguerrida, a Eva de todos os gaúchos.

\section{Referências}

AMOSSY, Ruth. Da noção retórica de ethos à análise do discurso. In: . (Org.). Imagens de si no discurso: a construção do ethos. São Paulo: Contexto, 2008. p. 9-28.

BARONAS, Roberto Leiser; BONATTI, Júlio. Imagens de autor de Noam Chomsky. In: BARONAS, Roberto Leiser et al. (Org.). Análise do Discurso: entorno da problemática do ethos, do político e de discursos constituintes. Campinas, SP: Pontes, 2016.

BAUMAN, Zygmunt. Identidade: entrevista a Benedetto Vecchi. Tradução de Carlos Alberto Medeiros. Rio de Janeiro: Jorge Zahar, 2005.

BOURDIEU, Pierre. O poder simbólico. Tradução de Fernando Tomas. Lisboa: Difusão Editorial; Rio de Janeiro: Bertrand Brasil, 1989.

DE CERTEAU, Michel. A cultura no plural. Tradução de Enid Abreu Dobránszky. Campinas, SP: Papirus, 1995.
FACIN, Débora. O enlaçamento enunciativo de um ritual carnavalizado: cenografia e ethos discursivo em sambas-enredo de escolas carnavalescas do meio-oeste catarinense. 2012. 119 f. Dissertação (Mestrado em Letras) - Programa de Pós-Graduação em Letras, Universidade de Passo Fundo, Passo Fundo, 2012.

FARINA, Geraldo. História de Nova Prata $R S$. Caxias do Sul: Educs, 1986.

FARINA, Geraldo. Memórias do cotidiano. Porto Alegre: Comunicação Impressa, 1987.

FREITAS, Ernani Cesar de. Linguagem na atividade de trabalho: éthos discursivo em editoriais de jornal interno de empresa. $D e$ senredo, Passo Fundo, v. 6, n. 2, p. 170-197, jul./dez. 2010.

Práticas de linguagem na atividade de trabalho: cenografia e ethos em discursos socioprofissionais. Revista Latinoamericana de Estudos do Discurso, Colombia, v. 11, n. 2, 2011.

GALEAZZI, Zaira. O violino do Fuá. In: . Sonho italiano: vinho e amor. Nova

Prata: Jornal Popular, 2013. p. 11-63. 100 anos da cidade de Nova Prata (1895-1995). [S.l.: s.n.], [199?].

GEERTZ, Clifford. A interpretação das culturas. 1. ed. 13. reimp. Rio de Janeiro, RJ: LTC, 2008.

GHIDINI, Ophélia Sander. Homenageando os 120 anos da Imigração Italiana. In: GALEAZZI, Zaira. 100 anos da cidade de Nova Prata (1895-1995). [S.l.: s.n.], [199?]. p. 201-202.

HALL, Stuart. Quem precisa da identidade? In: SILVA, Tomaz Tadeu da (Org.). Identidade e diferença: a perspectiva dos estudos culturais. 13. ed. Petrópolis, RJ: Vozes, 2013. p. 103-133.

HEBREUS. Natureza da fé. In: BÍBLIA SAGRADA. 36. ed. São Paulo: Edições Paulinas, 1980. p. 1314-1316. 
MAINGUENEAU, Dominique (1987). Novas tendências em análise do discurso. 3. ed. Tradução de Freda Indursky. Campinas: Pontes; Editora da Unicamp, 1997.

. (2000). Análise de textos de comunicação. Tradução de Cecília P. de Souza-e-Silva e Décio Rocha. São Paulo: Cortez, 2002.

. (1984). Gênese dos discursos. São

Paulo: Parábola, 2008a.

. (2005). Ethos, cenografia, incorporação. In: AMOSSY, Ruth (Org.). Imagens de si no discurso: a construção do ethos. Tradução de Dilson Ferreira da Cruz, Fabiana Komesu e Sírio Possenti. São Paulo: Contexto, 2008b. p. 69-92.

. (2006). Cenas da enunciação. São

Paulo: Parábola, 2008c.

. Doze conceitos em análise do discurso. Tradução de Adail Sobral et al. São Paulo: Parábola, 2010.

. (2000). Análise de textos de comunicação. 6. ed. Tradução de Cecília P. de Souza-e-Silva e Décio Rocha. São Paulo: Cortez, 2013.

A propósito do ethos. In: MOTTA, Ana Raquel; SALGADO, Luciana (Org.). Ethos discursivo. 2. ed. São Paulo: Contexto, 2015. p. 11-30.

NOVA PRATA. Histórico. Nova Prata: Administração Municipal, 2013/2016. Disponível em: < http://www.novapratars.com.br/site/sobre.php\#conteudo $>$. Acesso em: 23 jun. 2015.

SECRETARIA MUNICIPAL DE EDUCAÇÃO E CULTURA DE NOVA PRATA. $M u$ lheres e Memórias. Nova Prata, RS, 2009. 1 vídeo.

SILVA, Tomaz Tadeu da. A produção social da identidade e da diferença. In: (Org.). Identidade e diferença: a perspectiva dos estudos culturais. 13. ed. Petrópolis: Vozes, 2013. p. 73-102.
WOODWARD, Kathryn. Identidade e diferença: uma introdução teórica e conceitual. In: SILVA, Tadeu Tomaz (Org.). Identidade e diferença: a perspectiva dos estudos culturais. Petrópolis: Vozes, 2013. p. 7-72. 